\title{
Validating a Measure of Ethnic Identity in Afro-Caribbean American Students
}

\author{
Keisha V Thompson*
}

Assistant Professor, Kingsborough Community College, Behavioral Sciences and Human Services, USA

\begin{abstract}
The purpose of this study was to validate the Multi group Ethnic Identity Measure (MEIM) on a sample of AfroCaribbean American college students. This investigation is unique in that it disaggregated the data to go beyond the usual labels of Black and African American used in past validation studies. Due to being subsumed in the past under such monikers, information on the ethnic identity of Afro-Caribbean American college students has largely been missing from the literature. This investigation served as a comparison to past investigations on ethnic identity in populations of African descent. The results of this study indicated that the structure of the MEIM is consistent in this population. However, the results also indicated that ethnic identity does not have the same relationship with selfesteem and depression as it has in previously studied Black/African American and minority populations in the United States. The uniqueness of this population as well as the distinctive study results are discussed.
\end{abstract}

Keywords: Ethnic identity; Caribbean; Self-esteem; Multicultural

\section{Introduction}

The Multigroup Ethnic Identity Measure (MEIM) is a widely used instrument on adolescents and adults representing diverse ethnic groups [1]. The construct of ethnic identity as used in the MEIM is defined as a common phenomena across diverse ethnic groups, which include self-identification as a group member, a sense of belonging, and attitudes toward one's group [2]. Despite its wide usage, there is a paucity of empirical knowledge about the structure and measurement of the MEIM with respect to specific ethnic or racial groups [1] such as Afro-Caribbeans. This paucity of research reflects larger problems in the racial and ethnic literature: inadequate measurement of the construct of ethnic identity, and disagreement in the psychological literature between the constructs of ethnic and racial identity. Ponterotto and Mallinckrodt [3] challenged the field of counseling psychology to carefully reexamine the interrelationships between theory, measurement strategies, and instruments of racial and ethnic identity.

Within the field of counseling psychology, theory as it relates to racial and ethnic identity development has advanced, but there has been a failure to advance the methodology (Ponterotto and Mallinckrodt, Introduction to the Special Section on Racial and Ethnic Identity in Counseling Psychology: Conceptual and Methodological Challenges and Proposed Solutions [3]). The lack of research on the ethnic identity of Afro-Caribbean college students is a case in point of the failure of the field to reexamine existing theory and measurement strategies. Multicultural theory and literature has moved from Black and White racial comparisons, to focusing on the cultural experiences of minority culture and its implications such as acculturation and within group differences (Ponterotto and Mallinckrodt, Introduction to the Special Section on Racial and Ethnic Identity in Counseling Psychology: Conceptual and Methodological Challenges and Proposed Solutions [3]). With the exception of some dissertation studies, there has not been a generation of knowledge, studies and publications about Caribbean college students in the United States. It is possible that this population may often be subsumed under the African-American or Black population in research studies. Janet Helms [4] observed that other than to say that participants "self-identified", researchers do not adequately describe the racial or ethnic composition of their samples.
They also tend to assign participants to a racial or ethnic group without demonstrating how the assignment was determined [4].

Ponterotto and Park-Taylor [3] suggest to researchers that it may be wise to disaggregate data from individuals and groups who may share the Black designation but vary in terms of their identities and experiences in the United States. For example, Cokley explains that specifically for African Americans, the development of racial or ethnic identity is a result of their minority status. As will be demonstrated later in the literature review, many individuals and populations of African descent outside of the United States do not have minority status in their countries of origin. As a result of this significant distinction, it is possible that the construct of ethnic identity as defined and measured by the MEIM may not be accurately measured and defined in Afro-Caribbean college students in the United States. The purpose of this study was to validate the MEIM on Afro-Caribbean college students. The results of this investigation should provide information about the valid use of the MEIM as a measure of ethnic identity in this population. Results of this investigation will contribute to the psychological literature and inform practice as it relates to this growing population. It will also offer insight into ethnic identity development in Afro-Caribbean individuals in the United States.

Caribbean immigration to the United States from the English speaking islands and Haiti increased substantially after the change in the United States immigration laws in 1965 [5]. According to the 2012 American Community Survey 1-Year Estimates, there were 2,758,050 West Indian (Caribbean) non-Hispanic individuals in the United States; with the majority of these being of African descent [6]. Of this number 887,407 are enrolled in educational institutions. The survey

*Corresponding author: Keisha V Thompson, Assistant Professor, Kingsborough Community College, Behavioral Sciences and Human Services, USA, E-mail: Keisha.Thompson@kbcc.cuny.edu

Received November 02, 2016; Accepted November 17, 2016; Published November 24, 2016

Citation: Thompson KV (2016) Validating a Measure of Ethnic Identity in AfroCaribbean American Students. J Ment Disord Treat 2: 128. doi:10.4172/2471. 271X.1000128

Copyright: $\odot 2016$ Thompson KV. This is an open-access article distributed under the terms of the Creative Commons Attribution License, which permits unrestricted use, distribution, and reproduction in any medium, provided the original author and source are credited. 
estimates that $36.6 \%$ of Caribbean individuals over the age of 3 are enrolled in college or graduate school, of the greater population over the age of 25 , less than $20 \%$ do not have a high school diploma [6].

Even so, Afro-Caribbean students are underrepresented in higher education. Afro-Caribbean students are rarely identified or mentioned in research on Black college students in terms of their overall adjustment and achievement. These students are also not included or identified in research concerning immigrant or international students. Unlike those of other immigrants, they encounter a higher education system in which they are a distinct minority (Hine-St. Hilaire 2006). Afro-Caribbean students are also different, in that they speak English or may lack the distinct accents of their parents, and are identified racially by others [7]. Afro-Caribbean students are also of various generation statuses [5]. Those considered to be first generation may fall into three categories; (a) they immigrated to the United States as adults, (b) they immigrated to the United States as children and have been a part of the educational system prior to college, and (c) they are in the United States strictly to get an education and return to their home countries. The second generation students are those born in the United States to parents who emigrated from the Caribbean. The generational status of students further contributes to the complexity of understanding the experiences of Caribbean students.

Afro-Caribbean students are often studied in homogeneous samples identified by the monikers "Black or African American", and little to no research has contributed to the knowledge of ethnic identity in this population. This may be based on the similar phenotypic expression of genes in most individuals of African descent. In an effort to bring a nuanced view, the literature reviewed in this research will focus on ego identity development and ethnic identity as it has been studied in Black adolescents and college students. Ego identity development was utilized by Jean Phinney in her development of the Multigroup Ethnic Identity Measure (MEIM). Phinney's theory utilizes Erikson's ego identity development theory conceptualized by Marcia as its theoretical foundation. What follows is an explanation of each theory, and how it has been studied and applied to Black college students. A brief explanation of Afro-Caribbean identity is also included. Due to the lack of research and application of ethnic identity theory to AfroCaribbean students, a comparative explanation is offered in terms of African American adolescents as a benchmark.

\section{Ego Identity Development Theory}

Research on identity formation has focused on ego or personal identity and reference group orientation. The theory of ego identity development that is commonly used in Psychology is that of Erik Erikson. Erikson proposed eight critical periods of development of the human life cycle commonly referred to as psychosocial tasks. Erickson's theory purports that as an individual matures, he or she needs to negotiate each task before moving on to the later stages of development. Successful negotiation of each stage is critical towards becoming a psychologically healthy individual. Erikson posits that a lasting ego identity cannot be established without the trust of the first stage and the successful completion of the subsequent phases through adulthood. The stages begin at birth through age 18 months, where the infant negotiates between trust and mistrust. Erikson asserts that development of trust is dependent on how responsive and consistent the parent is with basic needs being met. This is particularly true on the areas of care and food. The premise of this is that the infant must first form a trusting relationship with the parent in order for mistrust to not develop. As a toddler (ages 18 months to 3 years), the negotiation between autonomy and shame/doubt occurs. This stage is the beginning of the development of self control and self confidence for children. This negotiation takes place in tasks such as toilet training, and children feeding and dressing themselves. Parents facilitate their children's development by not being overprotective at this stage, as the level of protectiveness will influence the child's ability to successfully negotiate this stage. The adverse effect of parents being overprotective is that the child will develop shame and doubt in his/her abilities. During the initiative versus guilt (ages 3 to 6 years) stage, the child continues to take initiative and are typically eager for responsibility. If this is not encouraged, the child will believe that what they want to do is wrong and develop a sense of guilt. The next stage of industry versus inferiority (ages 6 to 12 years) is marked by the child's need to be productive in several areas and to do work on their own. The areas of importance during this time are academics, group activities and friends. Difficulty with any of these leads to a sense of inferiority. The fifth stage takes place during adolescence and the negotiation is between identity and role confusion. Marcia proposed that the formulation of psychosocial identity takes place here. The adolescent child strives to achieve a sense of identity in occupation, sex roles, politics, and religion.

Ego identity development theory stresses the importance of an active search for identity during adolescence. The most utilized operationalization of Erikson's work has been Marcia's identity status model. Various researchers [8] have utilized this model to examine identity in college students. The traditional college student enters college where they may be transitioning from adolescence to young adulthood. This period of development is extrapolated in Marcia's theory.

Marcia proposed that adolescents and young adults can typically be categorized as being in one of four ego identity statuses: identity achievement, foreclosure, moratorium, and diffusion. In establishing identity achievement, Marcia used the variables of crisis and commitment to operationalize Erikson's theory. It is important to note that the statuses in this theory all take place within the identity vs. role confusion stage. The status of the individual is determined by the two variables of commitment and crisis. Crisis is the period of engagement where exploration and commitment takes place. Each identity status is characterized by the degree of exploration and commitment to ideological and interpersonal issues [9]. The foreclosure status is defined by the presence of commitment, but without self-exploration having taken place. The individual at this status may base their commitment on family values and beliefs without exploring alternatives of their own. The diffusion status does not entail exploration or commitment, it can be considered as being pre-crisis [9]. The moratorium status is characterized by an active search and exploration process, but no commitment is made. The identity achievement status is characterized by the presence of exploration and a commitment to whatever issue is at stake. The ego identity statuses represent the degree to which selfconcept or individual identity has been achieved as a unique individual living in the larger society. It is a major part of self-concept. In his work with elementary school children, Burnett provides discrepant definitions for self concept and self-esteem; two constructs that are often used interchangeably:

Self concept can be defined as the descriptive and evaluative beliefs that (children) have about significant multidimensional characteristics of the self, while self esteem is the global thoughts and feelings that children have about themselves as people, i.e. how much they like themselves (Table 1).

Another level of self-concept is that of a collective identity; the 
Citation: Thompson KV (2016) Validating a Measure of Ethnic Identity in Afro-Caribbean American Students. J Ment Disord Treat 2: 128. doi:10.4172/2471-271X.1000128

Page 3 of 9

\begin{tabular}{|c|c|c|c|c|c|c|}
\hline Self-Esteem & Explore & Affirm & Total MEIM & $\mathbf{R}^{\mathbf{2}}$ & $\mathbf{R}^{\mathbf{2}}$ & .183 \\
\hline Pearson correlation & .148 & .179 & .174 & .033 \\
\hline P value & .031 & .011 & .014 & .021 \\
\hline
\end{tabular}

Table 1: Correlations of Self Esteem and MEIM ( $N=161)$.
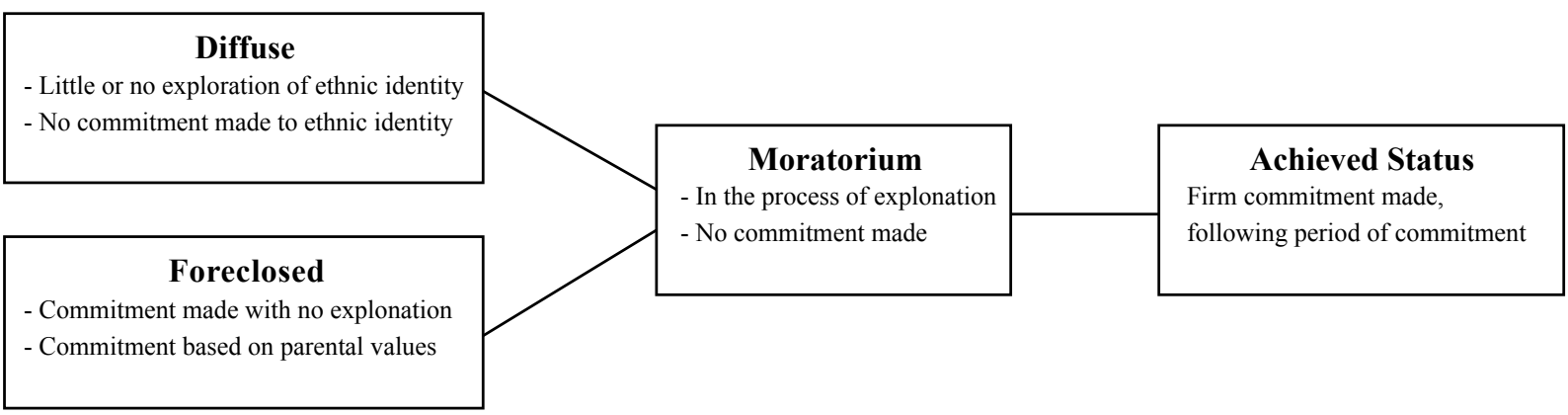

Figure 1: Phinney's Model of Ethnic Identity Development

collective identity is a significant component of one's self-concept, especially for members of non-dominant demographic groups [10]. For people of color, the collective identity may become a psychologically central or salient part of the self-concepts due to a given socio-political history [10]. The collective identity has been labeled as cultural, ethnic, racial, and group identities. Group identity is considered to consist of cognitive, evaluative and emotional components. The cognitive component is in the group members' awareness that they belong to a minority group which is markedly separate from other groups and they cannot rid themselves of their membership in the group. The value connotations associated with membership in a minority group makes up the evaluative component. Value connotations according to Tajfel [10] include minorities being socially disadvantaged, comparison of their social position and circumstances as compared with other groups, and favorable or unfavorable judgments about the group. The emotional component is the way the individual feels about his group membership. Tajfel [10] posits that when evaluations are negative and one cannot leave the group, a range of attitudes and strategies can be expected to occur such as a negative identity and self-hatred. The interaction of individual and group identities can be explored with the construct of ethnic identity.

\section{Phinney's Model of Ethnic Identity}

A precursor to understanding ethnic identity is an understanding of ethnicity. Ethnicity is a socially constructed concept, referring to the characterization of a group of people who are perceived by themselves and others as having a common ancestry, shared history, shared traditions, and shared cultural traits such as language, beliefs, values, music, dress and food. These cultural traits, traditions and values are often transmitted across generations. Phinney [11] identified culture, ethnic identity, and minority status as three psychological components of ethnicity.

Phinney's conceptualization of ethnic identity is composed of two parts. The first component is a stage model that is based on Marcia's operationalization of ego identity theory. Phinney's stage model of ethnic identity utilizes Marcia's model of ego identity development as a framework for ethnic identity development in ethnic minorities. Phinney's model follows the logic of Marcia's in that identity achievement occurs at the end of a process which has been initiated by some form of a crisis. The model is similarly based on the degree of exploration, and commitment in each stage. In the case of ethnic identity development, a crisis refers to a period of engagement where the individual may choose among meaningful alternatives within an ethnic identity. The individual moves from a stage of diffusion to exploration, and finally ethnic identity achievement. The stage at which there is neither exploration nor commitment is referred to as diffusion; the moratorium is the stage of exploration, and finally the individual should be able to gain ethnic identity achievement. Phinney has applied the same statuses of Marcia's model to ethnic identity development and presents them as stages. Figure 1 in the appendix summarizes Phinney's [12] stages of ethnic identity development.

In the Diffuse stage, an individual may or may not have made a commitment to their ethnic identity. In the case of someone who may be in the diffuse stage, there has been no engagement in exploration, and no commitment made. Some characterizations of this stage are a preference for the dominant culture, and little thought or interest given to ethnicity. On the other hand, someone in the foreclosed stage may have a committed ethnic identity, but it was not as a result of exploration; it may be due to parental influence and transmission of values [12]. Positive ethnic attitudes may have been absorbed from parents or other adults, and an individual may not show a preference for the majority group although they have not thought through the issues for themselves [12]. Depending on the socialization experience, feelings in both of these cases may be either positive or negative regarding one's own ethnicity [11].

Moratorium, the second stage is evidenced by exploration, and some confusion about the meaning of one's ethnicity [12]. This stage may take place as the result of a significant experience that forces an awareness of one's ethnicity, which is followed by an intense process of immersion in one's own culture. This immersion process involves participating in activities such as reading to understand more about one's ethnic group, talking to people who share the same ethnicity, going to ethnic museums, and participating actively in cultural events [11]. Although a commitment has not yet been made, the individual may begin to reject values of the dominant culture.

The final stage, achieved ethnic identity status, is characterized by a clear, secure understanding and acceptance of one's ethnicity [12]. After going through the exploratory stage, there is a deeper understanding and appreciation of one's own ethnicity. This stage 
may require resolution or coming to terms with cultural differences between the ethnic group of origin and the dominant culture group; as well as the lower status of one's own ethnic group in society [11]. Ethnic identity achievement does not necessarily imply a high degree of ethnic involvement; as individuals could be clear about their ethnicity without wanting to maintain the ethnic language or customs of their groups of origin [11]. This is why it is important to understand the meaning of ethnicity and the various components that compose ethnic identity. Phinney explains that:

There are at least three aspects of ethnicity that may account for its psychological importance. These include (a) the cultural values, attitudes, and behaviors that distinguish ethnic groups; (b) the subjective sense of ethnic group membership (i.e., ethnic identity) that is held by group members; and (c) the experiences associated with minority status, including powerlessness, discrimination, and prejudice [2].

The second component of Phinney's model focuses on cultural values, attitudes, and behaviors that distinguish ethnic groups and the subjective sense of ethnic group membership. The model lacks a clearly defined relationship of the stages of ethnic identity development with the aspects of ethnic identity. While it is clear that a higher score on the MEIM represents ethnic identity achievement, it is not clear how scores can be translated into the other stages of ethnic identity development. The items of the measure also do not directly address the aspect of minority status and the related experiences. Cokley does offer, however, that the components of this model are not mutually exclusive and overlap with one another. The overlap is apparent in the first two psychological components but not in the aspect of minority status. This aspect may be where Afro-Caribbean individuals differ from some minority groups in the United States.

Afro-Caribbean individuals in the United States can be classified as a voluntary minority group. Voluntary minority groups are those who moved willingly to the United States in the hope of a better future and do not believe that their status on the society is forced [13]. Ogbu and Simons goes on to explain that involuntary minority groups are those who were conquered or enslaved and interpret their status in society as being forced on them by White people. The unique socio-political experiences of Afro-Caribbean individuals will be extrapolated in a later section of this literature review.

\section{Multi group Ethnic Identity Measure (MEIM)}

The MEIM is Phinney's operationalized stage model of ethnic identity achievement in minority-group adolescents [14]. It was created as a measure of exploration and commitment using an existing ego identity development instrument as a starting point. The scale has been revised several times, and the current version that is most widely used consists of 12 items with response items included on a 4-point Likert-type scale.

A major conceptual question in ethnic identity research is whether or not the uniqueness of each group makes it impossible to generalize the measurement of ethnic identity [2]. Phinney introduced the MEIM to the psychological literature in an article published in 1992. In that study, Phinney focused on examining ethnic identity as a general phenomenon relevant to diverse groups.

The MEIM was conceptualized to measure three components of ethnic identity that are believed to be common across groups; affirmation and belonging, ethnic identity achievement, and ethnic behaviors [2]. Self-identification is assessed as well, and refers to the label that one gives to themselves as a member of an ethnic group [12]. This is not a scored component, rather participants are asked to self-report their ethnicity. The other components are derived from the scored response of the 12 items. The component of affirmation and belonging refers to the sense of group membership and attitudes toward the individual's group [15]. Belonging to a group, and having knowledge of its history and traditions becomes meaningful when there is a process of exploration and ultimately a clear and confident identification of one's ethnicity. Ethnic identity achievement, as previously discussed, is the extent to which an individual has a clear and confident sense of their ethnicity. Ethnic identity achievement is conceptualized as a continuous variable, ranging from the lack of exploration and commitment to evidence of both [2]. Ethnic identity achievement is based on a sense of belonging to an ethnic group with a common history, culture and customs. The MEIM assesses both for involvement in social activities with members of one's group as well as participation in cultural traditions [2]. Ethnic behaviors are activities associated with group membership such as participating in activities and traditions specific to the ethnic group [15].

Phinney's [2] ethnic identity model and measure has been used and validated with a number of ethnic groups. The original construction and validation was completed with Asian American, African American, Hispanics, Caucasian and mixed background high school participants [2]. The results of the original investigation yielded a single factor model for ethnic identity, due to the sub-factors of affirmation/belonging and ethnic identity achievement scales being highly correlated (.52), and no coefficients being found for ethnic behaviors. Although the exploratory factor analysis done by Phinney found one factor, correlations among the three components were examined.

A follow-up study and validation of the MEIM was conducted by Roberts et al. [15]. The results of this study introduced a two-factor model for the MEIM. Roberts' study utilized a larger sample than the original MEIM study done by Phinney. This study's sample size allowed for both an exploratory and confirmatory factor analysis of the structure within and across ethnic groups [15]. It was hypothesized that the results of this investigation would yield a two-factor model (affirmation/belonging and exploration) of the MEIM. This is based on Roberts' argument that ethnic behavior is not a part of major ethnic identity theories and may instead be considered to be an aspect of acculturation. The exploratory factor analysis in the Roberts et al. [15] study originally indicated three factors; however, one factor was made up of two items which was then eliminated because of model fit criteria. Subsequent analyses yielded two factors. Factor 1, labeled affirmation, belonging and commitment explained $51.2 \%$ of the total variance and included five items from the original affirmation/ belonging subscale and two items about commitment. Factor 2, labeled exploration explained $41.6 \%$ of the total variance and was made up of five items. Three of these items were from the original ethnic identity achievement scale, and two items were from the ethnic behaviors scale. The confirmatory factor analysis in Roberts and colleagues' [15] study also supported the hypothesized two-factor structure of the MEIM.

Other studies have utilized the MEIM in international samples such as Australian [16], Zimbabwean [17] and Korean individuals living in the United States and China [1]. Additional studies have been conducted with African American adolescents and college students $[9,18]$. However, to date, no such studies have been conducted with Afro-Caribbean individuals in colleges and universities or otherwise.

The current study will utilize the two factor structure introduced by Roberts and colleagues [15] and subsequently endorsed by Phinney 
[12]. The affirmation/belonging factor is based on the component of ethnic identity that includes a sense of belonging to an ethnic group and commitment to that group along with pride and positive feelings about the group [15]. The second factor of exploration is based on the process individuals experience in terms of exploring, learning about, and becoming involved in their ethnic group. Once the hypothesized factor structure is confirmed, each component will be examined independently. This will be done to confirm the assertion that although both factors tend to be highly correlated, they are each distinct aspects of ethnic identity [15].

\section{Afro-Caribbean American Identity}

In conducting this literature review, it was found that ethnic identity has been studied among Afro-Caribbean populations within the discipline of Sociology, much more so than in Psychology. In this regard, sociologist have found that, Afro- Caribbean students tend to assert a national-origin identity in order to distance themselves from a label they see as associated with negative stereotypes and discrimination, or to resist being categorized as African American [5]. Meaning that, despite being labeled as African American, these students self-identify as Jamaican, Haitian, Trinidadian, etc., reflecting their national identities and not their race [19]. This argument brings into consideration the ongoing debate in the psychological literature in regards to racial versus ethnic identity.

There is disagreement in the psychological literature concerning the constructs of ethnic and racial identity. Janet Helms, who developed the White Racial Identity Model as well as the Racial Identity Attitude Scale, states that some individuals use the term ethnicity as a euphemism and proxy for race [4]. Phinney used the term ethnicity because of the disagreement concerning the definition of race in psychology [8]. There is, however, agreement that race and ethnicity are social constructs that do not have objective, generally agreed upon scientific definitions $[13,20]$. Ethnicity is used to describe a group of people who have the same ancestral and historical origin and also share language, beliefs, values, music, and food. Race is used to describe similarities in the phenotypic expression of genes such as skin color, facial features and country/region of origin. Similarly, identity in each of these constructs is based on the sense of belonging, level of participation and evaluation of group membership for individuals. Researchers have found that Afro-Caribbean individuals identify in terms of ethnicity and not race [19].

Feliciano found that naturalized citizens and non-citizens are much more likely than those born in the United States to identify in national terms; non-citizens who have been in the United States less than 20 years are the most likely to identify solely with their country of origin instead of being identified as hyphenated Americans. Feliciano explains this influence of ethnic identities as being a result of characteristics such as gender, national origin and parents' birthplace. Hall and Carter [19], however, believe that Afro-Caribbeans have adopted negative stereotypes of what it means to be Black in America and prefer to not be associated with the African-American identity. These explanations can be understood in terms of their subjective perspectives. The sociological perspective offers that due to the focus placed on the color of one's skin, the ethnic identity of Afro-Caribbeans is often ignored [7]. The psychological perspective of ethnic identity is based upon models placed in the context of a racialized society. Afro Caribbeans have not been reared in a racialized society, but one based on class [7].

The Caribbean islands, very much like North America were initially populated by the native people, Amerindians before "discovery" and colonization. Slavery was also a part of the islands' histories; however, once slavery was abolished, the colonies consisted of mostly people of African descent. In countries like Trinidad, a colony of Great Britain, African descendents owned land and had a significant degree of independence [7]. Once slavery was abolished, the labor force came in the form of indentured servants from India and China. It is in this tradition that the Caribbean islands have continued to be diverse societies, with a hierarchical class structure in place [7].

The dichotomous social structure of the United States and the Caribbean creates complexity in the Afro-Caribbean individual's identity. The class structure in the Caribbean is a socially stratified community composed of the lower, middle, and upper classes [7]. One's position in a given community is based on how much money he or she has. Upward mobility is made possible by working very hard and acquiring homes and businesses [7]. The class system for the most part is not stratified by race and the majority population in the Caribbean is Black. When Afro-Caribbeans leave their countries of origin for the United States, they enter a racialized society in which they become a minority. Adjustment becomes difficult as they are denied the privileges and cultural status they enjoyed prior to migrating to the United States [7]. Unlike the class based society of their origin, AfroCaribbeans have difficulty moving out from the racial category in which they are placed based on the color of their skin in the racialized American society. Although they stress their nationality and ethnicity as Afro-Caribbeans, they face overwhelming pressures in the racialized United States to identify only as Black [5].

There is a lack of research on identity development among AfroCaribbean adolescents. What has been clear is that Afro-Caribbean adolescents are faced with a choice of whether to identify as American Blacks or to maintain an ethnic identity reflecting their parents' national origin [7]. What is not clear is when this choice in identity occurs. One indication is that of "reactive ethnicity," Feliciano describes this concept as ethnic identities being shaped by life experiences, such as political events or experiences of discrimination. As with the model of ego identity development and various models of ethnic and racial identity [2], shifts in identity transpire as crises occur. Because of the lack of research and information on ethnic identity development in Afro-Caribbean adolescents, what follows is a description of ethnic identity development in Black adolescents. The psychological literature has presented an aggregated view of this population, and the diversity within the Black population in the United States has not been reflected in the literature thus far.

\section{Ethnic Identity in Black Adolescents}

The identity development literature explores the development of the sense of self from childhood to adulthood. For Black individuals born in the United States, an important part of this sense of self is their ethnic identity. In a study of college students from four ethnic groups, Phinney and Alipuria [11] found that ethnic minority students rated ethnicity as a central identity concern, equal to religion and above politics. Aries and Moorehead found that among Black female adolescents, ethnicity was the domain most predictive of overall identity status and was regarded by participants as the area most important to self-definition. Research suggests that the stronger one's ethnic identity, the greater the contribution that identity makes to one's self-concept [2].

Research has found that members of racial minority groups, who are frequently disadvantaged and the targets of prejudice and 
discrimination, do not suffer from low self-esteem. Using social identity theory, Twenge and Crocker explain that when group identity is salient and their group is devalued or compared unfavorably with other groups; people try to attain a positive in-group identity by emphasizing the attractive aspects of their group. That is, they redefine negative stereotypical qualities as positive, and favor in-group members over out-group members. This theory may explain the positive correlation of ethnic identity with self-esteem, especially in Black children. Researchers have established that a positive relationship exists between ethnic identity and self-esteem [11]. To examine changes with age in ethnic identity and self-esteem, Phinney and Chavira [11] assessed 18 adolescents from three ethnic groups (Asian American, Black, and Hispanic) at age 16 and three years later. Results indicated that self-esteem and ethnic identity were significantly related at each time period that these constructs were assessed and across the three-year time span [2]. As previously discussed, the psychological literature has not addressed the relevance of ethnic identity to Afro-Caribbean individuals. When Afro-Caribbean individuals migrate to the United States, they become ethnic identity status becomes more relevant as they experience pressure from U.S. culture to identify as Black. The current investigation is a starting point for this unexplored area of research.

The purpose of this study is to validate the MEIM on a sample of Afro-Caribbean college students. The knowledge gained by this investigation will serve to fill the gap in the psychological literature regarding this population. Ethnic identity has been touted as an important aspect of development in people of color, but is often presented in a homogeneous form.

There have been a number of validation studies on the MEIM, mainly examining whether the instrument's structure is a two or three factor model. More recently results have indicated that it is consistently a two-factor model $[1,15,21]$. These studies however have done what experts in the topics of racial and ethnic identity have admonished researchers against doing. In reviewing the literature, one can make observations similar to those by Janet Helms [4]; researchers do not adequately describe the racial or ethnic composition of their samples beyond, Black, White, Asian, etc. They also tend to assign participants to a racial or ethnic group without demonstrating how the assignment was determined [4]. Furthermore, it is suggested by Ponterotto and Park [14] that data be disaggregated as a means of understanding the identities and experiences of individuals in the United States who share the common designation of Black. This study is adhering to the call by researchers to reevaluate the theory of ethnic identity and the manner in which it is measured. By disaggregating the Afro-Caribbean college student population, a more accurate view of this construct can be attained. This study is also adhering to the call by researchers to reevaluate the theory of ethnic identity and the manner in which it is measured.

\section{Participants}

Data on two hundred and twenty nine participants was drawn from a larger national study on culture and identity collected at 26 universities from across the United States. Students were included in this sample if (a) they were born in an English speaking Caribbean country, or (b) one or both parents were born in an English speaking Caribbean country. This data consisted of 155 students born in the United States and 74 not born in the United States. The average age was 20.42 years $(\mathrm{SD}=3.42)$, with a range from 17 - to 48 - years old consisting of 51 males and 180 females. The Caribbean countries represented were
Trinidad and Tobago, St. Kitts and Nevis, Jamaica, Barbados, Haiti, St. Croix- U.S. Virgin Islands, Guyana, Dominica, the Bahamas, St. Lucia, Turks and Caicos, Tortola- British Virgin Islands, Anguilla, St. Martin and St. Vincent.

\section{Measures}

\section{Multi group Ethnic Identity Measure (MEIM)}

The MEIM measures three aspects of ethnic identity; affirmation and belonging, ethnic identity achievement, and ethnic behaviors [2]. The scale consists of 12 items with responses on a 4-point Likert-type scale ranging from 1 (strongly disagree) to 4 (strongly agree). In this survey instrument, the scale ranged from 1 (strongly disagree) to 5 (strongly agree) and were re-coded as previously discussed. A higher score on the MEIM represents a more positive ethnic identity [2]. In this sample, the mean item score was 2.66 and the internal alpha reliability estimate was .89 .

\section{Rosenberg Self-Esteem Scale (RSE)}

The RSE measures self-acceptance [18]. It consists of 10 items on a Likert scale ranging from 1 (strongly disagree) to 4 (strongly agree). In the modified instrument used in this survey, the scale ranged from 1 (strongly disagree) to 5 (strongly agree), the data was re-coded as previously discussed. Higher scores represent higher self-esteem [18]. In this sample, the mean item score was 1.85 and the internal alpha reliability estimate was .81 .

\section{Center for Epidemiologic Studies Depression Scale (CES-D)}

The CES-D measures depressive symptomatology in the general population consisting of 20 items rated on 4 -point scale $(0=$ rarely or none of the time to $3=$ most or all of the time) (Radloff, 1977). In the modified instrument used in this survey, the scale ranged from 1 (strongly disagree) to 5 (strongly agree), the data was re-coded as previously discussed. Higher scores represent greater psychological distress (Radloff, 1977). In this sample, the mean item score was 1.42 and the internal alpha reliability estimate was .90 .

\section{Data Analysis}

\section{Confirmatory factor analysis}

A confirmatory factor analysis was conducted because past research has indicated that there is a need for confirmatory factor analysis assessments in diverse samples across race, ethnicity and age [3].

\section{Reliability and validity estimates}

The psychometric properties of the MEIM scales established in the confirmatory exploratory factor analysis were examined. The MEIM items from each factor were averaged separately to create scale scores, with higher scores representing a more positive ethnic identity. Then, the coefficient alpha for each scale was calculated to establish initial internal reliability estimates. And finally, the inter-correlations of the scales were examined, to establish initial construct validity.

\section{Ethnic identity, self-esteem and depression}

To establish concurrent validity, the relationship between selfesteem and depression were examined. Measures of self-esteem (RSE) and depression (CES-D) were utilized to examine their relationships with MEIM factors. Multiple regression analyses were performed to determine the unique contribution of each aspect of MEIM on selfesteem and depression. Self-esteem has been positively correlated with 
Citation: Thompson KV (2016) Validating a Measure of Ethnic Identity in Afro-Caribbean American Students. J Ment Disord Treat 2: 128. doi:10.4172/2471-271X.1000128

Page 7 of 9

ethnic identity in past studies of ethnic minorities [2]. Conversely, depression has been negatively correlated with ethnic identity [5].

\section{Group differences in ethnic identity}

Using analysis of variance (ANOVA), group differences were examined in the MEIM scales by gender and generation status (immigrant vs. U.S.-born). Past research has shown that females tend to score significantly higher on measures of ethnic identity than males. Hall and Carter [19] posit that studying within group differences on the basis of generational status has implications for how psychologists can work best with first and second generation Afro-Caribbean individuals.

\section{Results}

\section{Missing data}

Missing data in this study was handled by utilizing list wise deletions. This method was chosen based on the percentage of missing data. List-wise deletions are often thought of producing bias within analyses and also contributing to the loss of statistical power. This is especially true when data is not missing at random [22]. However, list wise deletion can produce unbiased parameter estimates when missing completely at random MCAR [23]. The missing data in this study was due to item non-response and appeared to be (MCAR). This was confirmed by the computation of Little's [24] MCAR test in SPSS using the missing value analysis [22]. This test implies that a non-significant $\mathrm{p}$-value indicates the data is MCAR [22,24]. In this case the p value was .57. There were 17 completely blank cases in the original data set and these were completely dropped from the analysis. Missing data ranged from a low of $2 \%$ for ethnic identity to a high of $23 \%$ for depression.

\section{Confirmatory factor analysis}

A CFA of MEIM scores using AMOS 16.0 was conducted to test the goodness of fit of Roberts' et al. [15] proposed two-factor model. The theoretical formulation for the proposed two factor model is based on Roberts' et al [15] investigation into the structure and construct validity of the MEIM. The two factors identified in Roberts et al. [15] were labeled affirmation/belonging and exploration. Based on this conceptualization five of the twelve items from the MEIM make up the subscale exploration. Items on this subscale demonstrate the extent, to which an individual is involved in their ethnic group, and explore and learn about it. The remaining seven items make up the subscale affirmation/belonging. Items on this subscale demonstrate an individual's sense of belonging to the group and positive feelings.

Two latent factors were constructed titled explore/search (5 items) and affirm/belong ( 7 items). MEIM items 1, 2, 4, 8, and 10 were loaded on the explore/search factor. MEIM items, 3, 5, 6, 7, 9, 11, and 12 were loaded on the affirm/belong factor [15]. The analysis revealed that the two factors were correlated at .83. The factor loadings ranged from .46, $\mathrm{R}^{2}=.21$ (item 1) to $.80, \mathrm{R}^{2}=.65$ (item 6).

Although there were 19 responses missing in the data, the maximum likelihood estimation function of AMOS assures multivariate normality in the distribution [9]. The chi square/ degrees of freedom ratio for this model was 2.34 with a probability level less than .05 . However the basis of goodness of fit will not be on this statistic as it can be restrictive in its assessment of only an exact fit [14]. The comparative fit index (CFI) was .94. The root mean square error of approximation (RMSEA) was .08.

\section{Reliability and validity estimates}

The psychometric properties of the MEIM affirm/belong and explore/search scales were examined. The affirm/belong scale had a mean item score of $1.89(\mathrm{SD}=.86)$ and a coefficient alpha of .89. These estimates are based on a sample size of 215 , with list wise deletions done by SPSS on 16 missing responses. The explore/search subscale had a mean item score of $2.95(\mathrm{SD}=1.10)$ and a coefficient alpha of .73 based on an $\mathrm{n}$ of 221 , with list wise deletions done by SPSS on 10 missing responses. Inter-correlations of the scales were examined, to establish initial construct validity along with the measures of selfesteem and depression.

\section{Ethnic identity, self-esteem and depression}

Measures for self-esteem (RSE) and depression (CES-D) were utilized to examine their relationships with MEIM factors. Multiple regression analyses were performed to determine the unique contribution of each aspect of MEIM on self-esteem and depression. Because of the random occurrence of missing responses in this dataset, the self-esteem and depression analyses were based on sample sizes of 161 and 153 , respectively.

Self-esteem: The mean score for self-esteem in this sample was 18.60 ( $\mathrm{SD}=7.85)$. The highest one can score on this scale is 40 . Selfesteem was positively correlated with the MEIM ( $\mathrm{r}=.17, \mathrm{p}=.01)$. Selfesteem was also positively correlated with the explore/search subscale, the correlation was $(\mathrm{r}=.15, \mathrm{p}=.03)$, and with the affirm/belong subscale $(\mathrm{r}=.18, \mathrm{p}=.01)$. Also the MEIM subscales were correlated with each other $(\mathrm{r}=1)$.

Depression: Participants mean score on the depression scale was 28.53 ( $\mathrm{SD}=14.68)$. The highest one can score on this scale is 68 . Depression was positively correlated with the explore/search subscale $(\mathrm{r}=.07, \mathrm{p}=.19)$, and with the affirm/belong subscale $(\mathrm{r}=.156, \mathrm{p}=.02$. It was also positively correlated with the MEIM measure as a whole $(\mathrm{r}=.113, \mathrm{p}=.08)$. These results are shown in Table 2.

\section{Group differences in ethnic identity}

Using analysis of variance (ANOVA), group differences were examined in the MEIM scales by gender and generation status (immigrant vs. U.S.-born). Separate one way ANOVAs were conducted with gender and each of the MEIM subscale. While there was homogeneity of variance for exploration $(\mathrm{p}=.35)$ and affirmation $(p=.22)$ the between subjects tests were not statistically significant. Similarly, with generation status, there was homogeneity of variance for exploration $(\mathrm{p}=.93)$ and affirmation $(\mathrm{p}=.15)$, but no statistical significance with the between subject tests.

\section{Discussion}

Little is known about Caribbean culture and identity in the fields of education and psychology [16]. The purpose of this study was to conduct an investigation in the area of ethnic identity in a sample of Afro-Caribbean college students. The goal was to contribute to the

\begin{tabular}{|c|c|c|c|c|c|}
\hline Depression & Exploration & Affirmation & Total MEIM & R & R Square \\
\hline Pearson correlation & .072 & .156 & .113 & .165 & .027 \\
\hline P value & .190 & .027 & .082 & \\
\hline
\end{tabular}

Table 2: Correlations of Depression and MEIM (N=153). 
psychological literature and inform practice as it relates to this growing population in the United States. The strategy for achieving this goal was centered on the validation of a widely used instrument of ethnic identity the MEIM.

The results of this study indicate that the MEIM is a two-factor structure for Afro-Caribbean college students. The items of the measure are in the appropriate categories of affirmation/belonging and exploration/search. Based on these results, it can be said that the MEIM measures the construct of ethnic identity appropriately based on the two-factor model. It is important to note that the factor loadings were stronger on the affirmation/belonging subscale than on the exploration/ search subscale. This may be due to the fact that two of the items on the affirmation/belonging subscale are from the ethnic behaviors subscale of the original MEIM. The results of the CFA illuminate how much is not known about ethnic identity in this population. Gaining an understanding of Afro-Caribbean students' experience and understanding of race, culture and ethnicity with open ended questions will give more concrete evidence of the appropriateness of the construct of ethnic identity for them.

Participants with higher scores on the MEIM measure, and the two subscales had higher scores on self-esteem. This finding is consistent with past research highlighting the importance of self-knowledge and feelings of belongingness to a group to a positive self-concept and self-esteem [13]. While statistically, this analysis confirmed the hypothesis that self-esteem will be positively correlated with MEIM and its subscales, the actual relationship between self-esteem and ethnic identity in this sample is a weak one [25]. The relationship between self-esteem and ethnic identity in this sample isn't as remarkable and supportive of past research where there has been a more distinct and robust relationship. This may be due to the different socialization experiences of Afro-Caribbean students in terms of the salience of group membership on identity development based on race or ethnicity.

Participants with higher scores on the affirmation subscale also had higher scores on depression. This is different from past studies in two regards. One being that depression is usually negatively correlated with ethnic identity $[15,17]$, and the other being that this study examined the bi-dimensionality of ethnic identity as measured by the MEIM. Utilizing the bi-dimensional approach highlighted the unique association of the affirmation aspect of ethnic identity development with depression. The correlation between affirmation and depression can be due to any number of reasons. Due to the ambiguity of the relationship between Phinney's stage model and the MEIM, a person's score on the subscales and measure does not indicate what stage of identity development they may be experiencing. Very much like its theoretical foundation of ego identity development, one may not be able to arrive at ethnic identity achievement without negotiating the exploration aspect of each stage. Additionally, in the case of Afro-Caribbean students, having national pride can have negative consequences in a racialized society. Students may be accused of trying to separate themselves from other minority groups, as well as being un-patriotic.

Having all of these experiences may lead to acculturative stress and depression. Students of Afro-Caribbean descent living in the United States experience some level of acculturation. As they learn about the culture of the United States and negotiate their own values and beliefs within this context, they experience some acculturative stress. Acculturative stress is stress associated with the adaptation process students are experiencing in the new culture [10]. The findings of this study indicate that the relationship between ethnic identity and depression may be mediates by another factor. It is likely that the mediating factor is acculturative stress.

There were no significant differences in participant MEIM total and subscale scores based on gender or generation status. This is counter to previous research that has shown females tend to score higher on ethnic identity than males $[11,12]$. A possible explanation for this is based on the unique experiences of Afro-Caribbean men and women in the United States. Past research the gender differences in ethnic identity achievement have been based on the presumption that the female members of ethnic groups often solely carry out traditions such as cooking and other rituals. While this may be true within the home, Afro-Caribbean males often seek out cultural experiences outside of the home. With Afro-Caribbean individuals participating in gender specific cultural tasks and rituals, ethnic identity achievement is not disproportionate based on gender.

The relevance and findings of the current investigation clearly shows that while ethnic identity is a common occurrence in identity development, it does not have the same general effects and implications for all minority populations. In this case, ethnic identity did not have the implications on self-esteem and depression in Afro-Caribbean students.

\section{Limitations and Future Research}

There were some limitations to this investigation. All of the measures collected were based on self-report. Additionally male participants were tremendously underrepresented accounting for about $22 \%$ of the sample under the best circumstances. Similarly the percentage of first generation students in this sample was $32 \%$. Such disparities indicate that the results of this investigation may not be accurately representative of the Afro-Caribbean college student population. Finally, analyses did not take in to account the region of the country participants were from as well as the length of time participants have been in the United States. Such information could potentially contribute to ethnic identity achievement as well as its relationship with self-esteem and depression.

Future research should be of a comparative nature. One example of this would be comparative analysis of ethnic identity and selfesteem and depression in diverse populations of African descent (i.e., Afro-Caribbean, African American, African), as well as to majority populations. Such comparative analysis could also include measures of racial identity development which would provide insight into the more racialized aspect of American society. Finally, because there is an extreme lack of knowledge in the area of Caribbean identity, qualitative studies in this area will also be useful.

\section{Acknowledgments}

This research is based on the author's dissertation study. The author wishes to thank Linda G. Castillo and Jamilia Blake for their support and guidance in the completion of this work.

\section{References}

1. Lee RM, Yoo HC (2004) Structure and measurement of ethnic identity for Asian American college students. Journal of Counseling Psychology 51 : 263-269.

2. Phinney JS (1992) The multigroup ethnic identity measure: A new scale for use with diverse groups. Journal of Adolescent Research $7:$ 156-176.

3. Ponterotto JG, Park-Taylor J (2007) Racial and ethnic identity theory, measurement, and research in counseling psychology: Present status and future directions. Journal of Counseling Psychology 54: 282-294.

4. Helms JE (2007) Some better practices for measuring racial and ethnic identity constructs. Journal of Counseling Psychology 54: 235-246. 
Citation: Thompson KV (2016) Validating a Measure of Ethnic Identity in Afro-Caribbean American Students. J Ment Disord Treat 2: 128. doi:10.4172/2471-271X.1000128

Page 9 of 9

5. Waters MC (1994) Ethnic and racial identities of second-generation Black immigrants in New York City. International Migration Review 28: 795820.

6. U.S. Census Bureau (2012) 2012 American community survey 1-year estimates, selected population profile: West Indian (excluding Hispanic origin groups).

7. Hine-St. Hilaire D (2006) Immigrant West Indian families and their struggles with racism in America. Journal of Emotional Abuse 6 : 47-60.

8. Phinney JS, Chavira V (1992) Ethnic identity and self-esteem:An exploratory longitudinal study. Journal of Adolescence 15: 271-281.

9. Jackson DL, Gillaspy JA, Purc-Stephenson R (2009) Reporting practices in confirmatory factor analysis: An overview and some recommendations. Psychological Methods 14:6-23

10. Thompson KV, Lightfoot N, Calsillo L, Hurst M (2010) Influence of family perceptions of acting white on acculturative stress in African American college students. International Journal for the Advancement of Counselling 32 : 144-152.

11. Phinney JS (1990) Ethnic identity in adolescents and adults: Review of research.Psychological Bulletin 108: 499-514.

12. Phinney JS (2001) Jean Phinney's Model of Ethnic Identity Development .Jean S. Phinney: California State University Los Angeles Psychology Department.

13. Smith TB, Silva $L$ (2011) Ethnic identity and personal well-being of people of color: Ameta-analysis. Journal of Counseling Psychology 58 : 42-60.

14. Ponterotto JG, Gretchen D, Utsey SO, Stracuzzi T, Saya R (2003) The multigroup ethnic identity measure (MEIM): Psychometric review and further validity testing. Educational and Psychological Measurement 63: 502-515.

15. Roberts RE, Phinney JS, Masse LC, Chen YR, Roberts CR, et al. (1999) The structure of ethnic identity of young adolescents from diverse ethnocultural groups. Journal of Early Adolescence 19:301-322.

16. Greenidge WL, Daire AP (2010) The relationship between emotional openness and the attitudes towards seeking professional counseling of English-speaking Caribbean college students. International Journal for the Advancement of Counselling 32: 191-201.

17. Walker RL, Wingate LR, Obasi EM, Joiner TE (2008) An empirical investigation of acculturative stress and ethnic identity as moderators for depression and suicidal ideation in college students. Cultural Diversity \& Ethnic Minority Psychology 14: 75-82.

18. Rosenberg M (1989) Society and the Adolescent Self-Image. Middletown,CT: Wesleyan University Press.

19. Hall SP, Carter RT (2006) The relationship between racial identity, ethnic identity, and perceptions of racial discrimination in an Afro-Caribbean descent sample. Journal of Black Psychology 32: 155-175.

20. Radloff LS (1977) The CES-D Scale: A self-report depression scale for research in the general population. Applied Psychological Measurement 1: 385-401.

21. Yap SC, Donnellan MB, Schwartz SJ, Kim SY, Castillo LG, et al. (2014) Investigating the structure and measurement invariance of the Multigroup Ethnic Identity Measure in a multiethnic sample of college students. Journal of counseling psychology 61: 437.

22. Schlomer GL, Bauman S, Card NA (2010) Best practices for missing data managementin counseling psychology. Journal of Counseling Psychology 57: $1-10$.

23. Enders CK (2001) The impact of nonnormality on full information maximum likelihoodestimation for structural equation models with missing data Psychological Methods 6: 352-370.

24. Little RJ (1988) A test of missing completely at random for multivariate data with missingvalues. Journal of the American Statistical Association 83: 1198-1202.

25. Kozak M (2009) What is strong correlation? Teaching Statistics 31: 85-86 